\title{
Active management of atrial fibrillation or flutter in emergency department patients with renal impairment is associated with a higher risk of adverse events and treatment failure
}

\author{
Frank X. Scheuermeyer, MD, MHSc ; Hubert Wong, $\mathrm{PhD}^{\dagger}$; Tyler W. Barrett, MD, MSCI ${ }^{\ddagger}$; Jim Christenson,
} $\mathrm{MD}^{*}$; Eric Grafstein, MD*; Brian Grunau, MD, MHSc${ }^{*}$; Matt Wiens, PhD*; Grant Innes, MD ${ }^{\S}$

\section{CLINICIAN'S CAPSULE}

What is known about the topic?

The influence of renal impairment upon emergency department-based outcomes in patients with atrial fibrillation or flutter (AFF) is unknown.

What did this study ask?

What was the impact of renal impairment upon adverse events $(A E)$ and rate and rhythm control (RRC) attempts in emergency department (ED) AFF patients?

What did this study find?

When ED AFF patients with renal impairment are administered RRC, they have more than $10 \%$ excess $A E$ risk.

Why does this study matter to clinicians?

Emergency physicians should be cautious about attempting $R R C$ in ED AFF patients with renal impairment.

\section{ABSTRACT}

Objective: Atrial fibrillation or flutter (AFF) patients with renal impairment have poor long-term prognosis, but their emergency department (ED) management has not been described. We investigated the association of renal impairment upon outcomes after rate or rhythm control (RRC) including ED-based adverse events $(A E)$ and treatment failure.

Methods: This cohort study used an electrocardiogram database from two urban centres to identify consecutive AFF patients and reviewed charts to obtain comorbidities, ED management, including $R R C$, prespecified $A E$, and treatment failure. Patients were dichotomized into a normal estimated glomerular filtration rate $(\mathrm{eGFR}) \geq 60 \mathrm{~mL} / \mathrm{min} / 1.73 \mathrm{~m}^{2}$ ) or impaired renal function ("low eGFR"). Primary and secondary outcomes were prespecified $\mathrm{AEs}$ and treatment failure, respectively. We calculated 1 ) adjusted excess $A E$ risk for patients with decreased renal function receiving $\mathrm{RRC}$; and 2) adjusted odds ratio of RRC treatment failure.

Results: Of 1,112 consecutive ED AFF patients, $412(37.0 \%)$ had a low eGFR. Crude AE rates for RRC were $27 / 238$ (11.3\%) for patients with normal renal function and 26/103 (25.2\%) for patients with low eGFR. For patients with low eGFR receiving RRC, adjusted excess AE risk was $13.7 \%$. (95\% Cl 1.7 to $25.1 \%$ ). For patients with low eGFR, adjusted odds ratio for RRC failure was 3.07. (95\% Cl 1.74 to 5.43 )

Conclusions: In this cohort of ED AFF patients receiving RRC, those with low eGFR had significantly increased adjusted excess risk of $A E$ compared with patients with normal renal function. Odds of treatment failure were also significantly increased.

\section{RÉSUMÉ}

Contexte: La fibrillation auriculaire et le flutter auriculaire (FFA) chez les patients atteints d'un dysfonctionnement rénal comportent un pronostic sombre à long terme, mais la documentation reste silencieuse sur leur prise en charge au service des urgences (SU). L'étude avait donc pour objet l'incidence du dysfonctionnement rénal sur les résultats cliniques après une réduction de la fréquence (RF) cardiaque ou une régularisation du rythme (RR) cardiaque, dont la survenue d'événements indésirables (EI) au SU ou l'échec du traitement.

Méthode: Il s'agit d'une étude de cohorte qui visait à repérer des patients consécutifs atteints de FFA, à l'aide de données sur les ECG recueillies dans deux grands centres urbains, et à examiner les dossiers médicaux à la recherche de renseignements sur les affections concomitantes; la prise en charge au SU, dont les traitements par RF/RR; les El prédéterminés et l'échec du

From the *Department of Emergency Medicine, St Paul's Hospital and the University of British Columbia, Vancouver, BC; †Centre for Health Evaluation and Outcome Science, University of British Columbia, Vancouver, BC; ¥Department of Emergency Medicine, Vanderbilt University Medical Center, Nashville, TN; and the §Department of Emergency Medicine, Rockyview Hospital and the University of Calgary, Calgary, AB.

Correspondence to: Frank X. Scheuermeyer, Department of Emergency Medicine, St Paul's Hospital and the University of British Columbia, 1081 Burrard St, Vancouver, BC, Canada V6Z 1Y6; Email: frank.scheuermeyer@gmail.com

(C) Canadian Association of Emergency Physicians

CJEM 2019;21(3):352-360

CAEP | ACMU
DOI 10.1017/cem.2018.475 
traitement. Les patients ont été divisés en deux groupes : fonctionnement rénal normal (débit de filtration glomérulaire estimé [DFGe] $\geq 60 \mathrm{ml} / \mathrm{min} / 1,73 \mathrm{~m}^{2}$ ) et fonctionnement rénal anormal (DFGe faible). Les critères principal et secondaire d'évaluation comprenaient des El prédéterminés et l'échec du traitement, respectivement. Ont été calculés 1) le risque excédentaire rajusté d'El chez les patients atteints d'un dysfonctionnement rénal qui ont été soumis à une $R F / R R$; et 2) le risque relatif approché [RRA] rajusté d'échec du traitement par RF/RR.

Résultats: Sur 1112 patients consécutifs examinés pour FFA au SU, $412(37,0 \%)$ avaient un faible DFGe. Le taux brut d'El après une RF/RR était de $27 / 238(11,3 \%)$ chez les patients ayant un fonctionnement rénal normal et de $26 / 103(25,2 \%)$

\section{INTRODUCTION}

Atrial fibrillation or flutter (AFF) are commonly encountered dysrhythmias. ${ }^{1}$ Most emergency department (ED) research has focused on patients with acute-onset $\mathrm{AFF}$ and determined that rate or rhythm control (RRC) are both safe and effective. ${ }^{2-8}$ However, in patients with $\mathrm{AFF}$ either provoked by or concomitant with an acute underlying illness, ${ }^{9}$ RRC has a higher chance of undesirable ED-based outcomes. ${ }^{10}$

Community AFF patients with renal impairment have higher rates of stroke and death, ${ }^{1-15}$ whereas ED patients with elevated creatinine have higher mortality. ${ }^{16}$ The recent CAEP guidelines ${ }^{4}$ do not mention patients with renal disease but given this elevated risk, we sought to investigate whether RRC was also associated with poor ED-based outcomes.

We analysed an ED AFF cohort and hypothesized that patients with renal impairment undergoing RRC would have more adverse events (AE) and higher rates of treatment failure.

\section{METHODS}

\section{Study design and setting}

This cohort study was conducted at two urban Canadian university-affiliated EDs. St. Paul's Hospital is a referral centre with 70,000 annual ED visits and comprehensive cardiology and renal services. Mount St. Joseph's Hospital is a community centre with 25,000 yearly visits and a general internal medicine unit. This is a secondary analysis of a previously described cohort ${ }^{10,17,18}$ approved chez les patients ayant un faible DFGe. Parmi ceux qui ont été soumis à une RF/RR dans ce dernier groupe, le risque excédentaire rajusté d'El s'est établi à 13,7\% (IC à 95\% : 1,7-25,1\%) et le RRA rajusté d'ET par RF/RR, à 3,07 (IC à 95\% : 1,74-5,43). Conclusion: Dans cette cohorte composée de patients atteints de FFA et traités par RF/RR au SU, ceux qui avaient un faible DFGe ont connu une augmentation importante du risque excédentaire rajusté d'El comparativement aux patients qui avaient un fonctionnement rénal normal. II en allait de même pour le RRA d'échec du traitement.

Keywords: Atrial fibrillation, patient safety, renal impairment by the Providence Health Care/University of British Columbia research ethics board.

\section{Patient selection}

During the study period, every electrocardiogram (ECG) conducted was stored in the MUSE (GE Healthcare Clinical Systems, Waukesha, WI) database, along with the patient's unique identifying number, and date and time of acquisition. A cardiologist confirms all ECGs within 24 hours. We interrogated the database to identify ED-based ECGs showing AFF between January 1, 2009 and December 31, 2009. ${ }^{10,17,18} \mathrm{We}$ entered this list into a spreadsheet (Excel, Microsoft Corporation, Redmond WA), removed all identifiers except the unique number, date, and time, and reviewed the ED chart. Each patient then had a chart review of the ED encounter.

\section{Exclusions}

We excluded patients with recent cardiac procedures because cardiologists or surgeons directed treatment, and those referred to the ED for direct specialty admission. We also excluded patients who re-attended the ED within 1 year, those from outside our six-ED health region, and those who only attended to monitor anticoagulation.

\section{Interventions}

ED physicians managed $\mathrm{AFF}$ patients at their discretion, including decisions to 1) order any investigations; 1) administer the following care: no RRC; rate control 
using intravenous or oral rate control agents; or rhythm control using oral or intravenous antiarrhythmic agents, or electrical countershock under procedural sedation; and 3) discharge or refer the patient.

\section{Testing of renal function}

Both hospitals used a rapid serum creatinine test on a blood gas analyser (Radiometer ABL800 Flex analyzer, Radiometer Canada, London, ON). To account for differences in gender and body mass, the estimated glomerular filtration rate (eGFR) was automatically calculated using the abbreviated Modification of Diet in Renal Disease (MDRD) equation, $\mathrm{eGFR}=175 \mathrm{x}$ $(\mathrm{SCr} / 88.4)^{-1.154} \mathrm{x}$ (age $)^{-0.203}$ for males, multiplied by 0.742 if the patient was female. ${ }^{19}$ Results were routinely available within 10 minutes.

\section{Data capture}

The sites share an electronic database that records patient demographics, triage complaint, and all ED investigations with results including eGFR. For each patient, emergency physicians completed an electronic discharge summary recording all diagnoses, medications administered, procedures, and consultations. The nursing record provided initial and all subsequent vital signs.

\section{Chart review}

We followed the criteria of Gilbert ${ }^{20}$ and Worster. ${ }^{21}$ Four reviewers blinded to study hypothesis and outcomes independently abstracted charts onto standardized electronic spreadsheets. ${ }^{10,17,18}$ We trained reviewers on the first 10 charts, the primary investigator was available at any time to discuss unclear data, and reviewers submitted blocks of charts on regular intervals. With the assistance of electronic records dating to 1999, we regularly clarified missing or discrepant data, and identified obvious issues such as a CHADS2 score $^{22}$ in an 80-year old patient. A second abstractor reviewed a random $10 \%$ of all charts, and we obtained kappa values for the key variable eGFR, dichotomized as greater or less than 60. A second staff emergency physician reviewed all potential $\mathrm{AE}$. In case of disagreement, two specialists independently reviewed the case.

\section{Outcomes and variable definitions}

The primary outcome was the number of patients with at least one $\mathrm{AE}$ within 4 hours of $\mathrm{RRC}^{10,17,18}$ or within 4 hours of arrival if no RRC was administered. These were defined according to prespecified criteria reflecting likely complications of RRC and classified into major and minor $\mathrm{AE}$ (Box 1). ${ }^{10,17,18} \mathrm{We}$ combined patients undergoing RRC, similar to a previous study using the same cohort. ${ }^{10}$ Patients with more than one $\mathrm{AE}$ were counted as having a single AE.

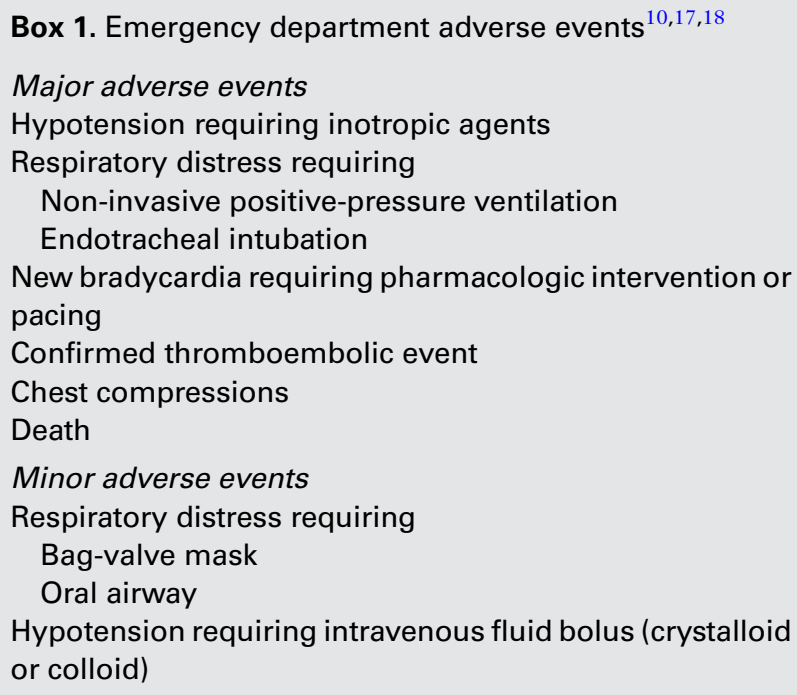

The secondary outcome was treatment failure with RRC. As per standards, successful rate control was defined as decreasing ventricular rate to 100 beats per minute or fewer ${ }^{4}$ within 4 hours of medication administration. (We did not distinguish resting or active heart rates.) Successful rhythm control was defined as establishment and maintenance of sinus rhythm in patients who had a rhythm control attempt. ${ }^{10,17}$

For all outcomes, we divided the cohort into patients with renal impairment (eGFR less than $60 \mathrm{~mL} / \mathrm{min} /$ $1.73 \mathrm{~m}^{2}$; "low eGFR") and patients without renal impairment (eGFR 60 or greater), as per the Kidney Disease/ Improving Global Outcomes (KDIGO) guidelines. $^{23,24}$ Because physicians might not have access to a prior eGFR value or a thorough medical history, we did not attempt to differentiate between chronic kidney disease $^{23,24}$ and acute kidney injury. ${ }^{25}$ Greenslade used a similar approach in an ED cohort of chest pain patients. ${ }^{26}$ Because physicians might not order an 
eGFR in well-appearing patients, we treated patients without an eGFR as having a normal value.

\section{Data analysis}

We used Microsoft Excel 2011 (Microsoft Corp, Redmond, WA) for data entry, and reported discrete variables were reported as percentages. We presented continuous variables as means with standard deviations or medians with interquartile ranges where applicable. We performed statistical analyses using SAS 9.3. (SAS Corporation, Cary, NC).

We compared risk of AE in low eGFR patients with the risk in normal-eGFR patients by several methods, as follows:

1) The adjusted causal risk difference is the excess risk of $\mathrm{AE}$ as a result of RRC administration in patients with low versus normal eGFR after adjustment for the presumed overall greater illness of the low eGFR population. Expressed another way, this is the $\mathrm{AE}$ rate if all $\mathrm{AFF}$ patients, dichotomized into low- and normal-eGFR groups, received RRC, minus the AE rate if no AFF patients received RRC.

2) The population attributable risk is the excess AE risk due to RRC use, compared with no RRC use, in patients with both low and normal eGFR after adjustment for comorbidities - or alternatively, the proportion of AEs that would not have occurred had RRC not been attempted. While similar to 1 ), this only measures patients who actually had RRC, rather than if, "all" patients had RRC.

3) The exposure effect is the excess AE risk when RRC is used in patients with low versus normal eGFR. (This only applies to patients who received RRC.) We used three different analyses because this is a heterogeneous group of acute and chronic AFF patients with and without acute underlying illnesses, and we also combined RRC treatments. Similar direction and magnitude of the association between eGFR and outcomes in each separate analysis would suggest a strong relationship between eGFR and outcomes of RRC.

Firstly, we calculated crude $\mathrm{AE}$ rates in patients who received RRC and those who did not and obtained crude risk difference. Secondly, we fit a logistic regression model for $\mathrm{AE}$ risk using the following: age, sex, prior AFF, hypertension, diabetes, initial systolic blood pressure, and use of RRC. Thirdly, we used the fitted model to estimate standardized (to the covariate distribution) risks under different exposure assumptions (actual exposure to RRC, if all patients were exposed to RRC, if no patients were exposed to RRC) and subgroups (all patients, and only those who received RRC) to calculate the previous three measures of effect (adjusted causal risk, population attributable risk, and exposure effect) and compare these effect measures between the low and normal eGFR groups. We used the percentile bootstrap method to obtain $95 \%$ confidence intervals (CI).

To analyse treatment failure, we calculated the adjusted odds ratio of treatment failure with RRC, comparing patients with low versus normal eGFR. We fit a logistic regression model for treatment failure as a function of normal versus decreased renal ability, using the same covariates.

In addition, we also conducted two further analyses: 1) a secondary analysis of patients with an initial heart rate $>100$ beats per minute (because they would be more likely to receive RRC), and 2) a sensitivity analysis for the cohort of patients with complete data, with all of the above outcomes.

\section{RESULTS}

During the 1-year study period, 1,508 consecutive patients had ECG-proven AFF, with 1,112 patient encounters meeting inclusion criteria (Figure 1). Overall, 966 patients (86.8\%) had an eGFR, and none of the 146 patients without this test were admitted to hospital. The kappa value for eGFR was 1.0 (95\% CI 0.97 to 1.0$)$ and 2 of 73 potential $\mathrm{AE}$ required adjudication.

Four hundred and twelve (37.1\%) patients (349 fibrillation and 63 flutter) had low eGFR. Patients with low eGFR were older with more comorbidities. Overall, 254 patients received rate control (151 beta-blocker, 93 calcium channel blocker, 10 digoxin), and 87 patients received rhythm control (50 electrical, 37 chemical) (Table 1). Rates of RRC were 238/700 (34.0\%) for patients with normal eGFR and 103/412 (25.0\%) for patients with low eGFR.

Unadjusted AE rates were as follows (Table 2): For patients with low eGFR, AEs occurred in 26/103 (25.2\%) who had RRC, and in 13/309 (4.2\%) who did not. For normal patients, the proportion was $27 / 238$ $(11.3 \%)$ and $7 / 462,(1.5 \%)$, respectively. (Unadjusted $\mathrm{AE}$ results for both low normal eGFR for both RRC 


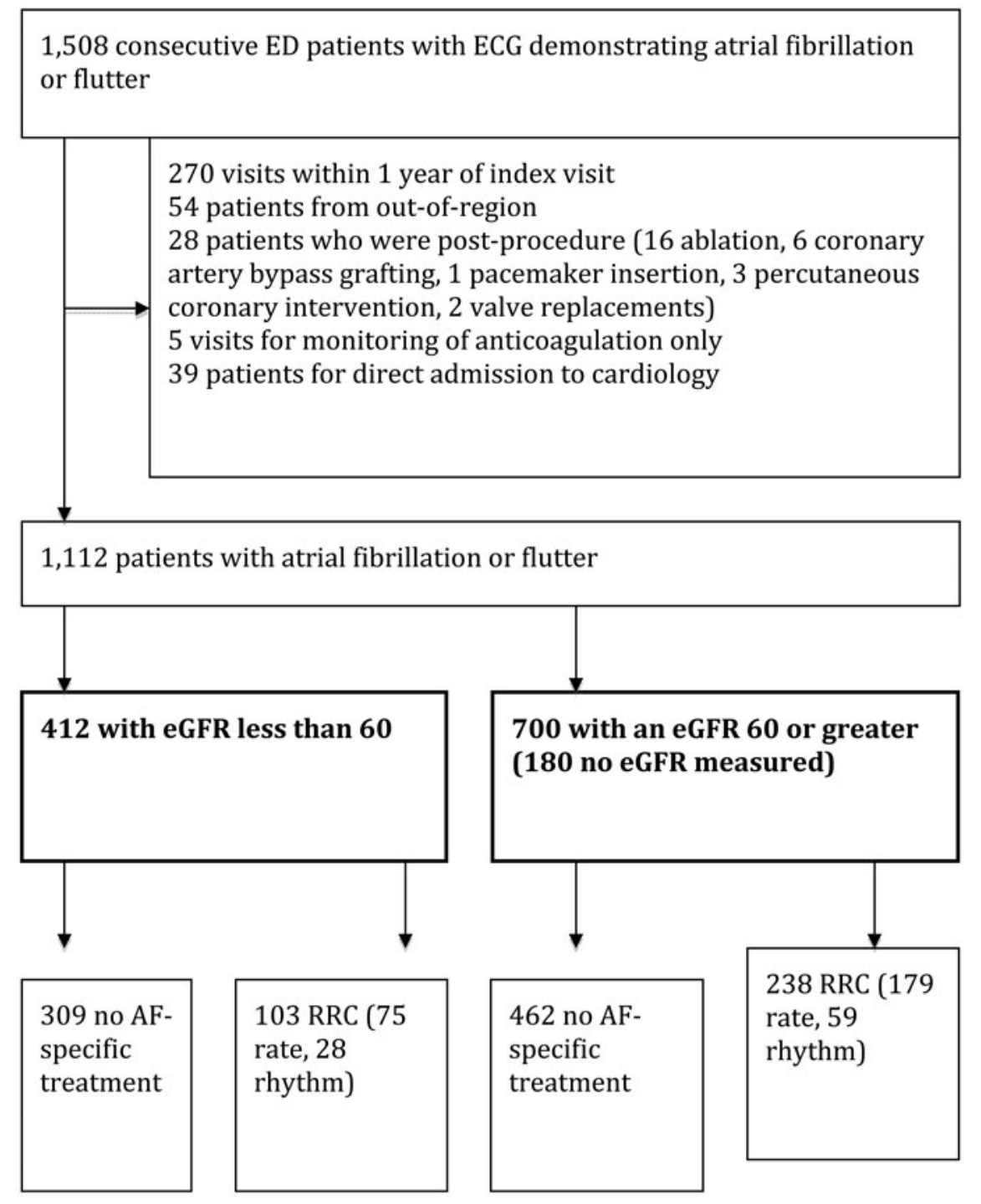

Figure 1. Study flow diagram.

and "no treatment" are significant at $p=0.05$.) The most common $\mathrm{AE}$ across all groups was "hypotension requiring fluid boluses" (Appendix 1), and patients receiving rhythm control had higher unadjusted $\mathrm{AE}$ rates than those receiving rate control. Unadjusted RRC failure rates were as follows (Table 3): 61/103 (59.2\%) in patients with low eGFR and 78/238 (32.8\%) for normal eGFR; treatment failures were higher for patients undergoing rhythm than rate control.

Appendix 2 displays demographics, comorbidities, treatments, and outcomes for stepwise eGFR categories: as renal function decreased, patients were older, had more comorbidities, and had higher unadjusted rates of $\mathrm{AE}$ and treatment failure. The risk of $\mathrm{AE}$ (independent of whether patients received RRC) in patients with
eGFR $\geq 60$ was $34 / 700$ (4.9\%) compared with $8 / 173$ (4.6\%) in patients with eGFR 45-59, 13/135 (9.6\%) in patients with eGFR 30-44, and 18/104 (17.3\%) in patients with eGFR $<30$. Among patients undergoing $\mathrm{RRC}$, the AE risk was $27 / 238$ (11.3\%) in patients with eGFR $\geq 60,6 / 50 \quad(12 \%)$ for eGFR 45-59, 9/31 $(29.0 \%)$ for eGFR 30-44, and 11/22 (50.0\%) for eGFR $<30$. The risk of treatment failure for patients undergoing RRC was 73/238 (30.6\%) in patients with eGFR $\geq 60,18 / 50$ (36.0\%) for eGFR 45-59, 22/31 $(71.0 \%)$ for eGFR $30-44$, and $16 / 22$ for eGFR < 30 .

For the adjusted outcomes, we excluded 81 (7.3\%) patients from the primary analysis due to missing covariates. For patients with low eGFR, the excess causal risk difference for $\mathrm{AE}$ in patients with low eGFR who 


\begin{tabular}{|c|c|c|}
\hline $\begin{array}{l}\text { Characteristic, n (\%) } \\
\text { unless specified }\end{array}$ & $\begin{array}{l}\text { eGFR less } \\
\text { than } 60\end{array}$ & $\begin{array}{l}\text { eGFR } 60 \text { or } \\
\text { greater }\end{array}$ \\
\hline \multicolumn{3}{|l|}{ Demographics } \\
\hline Age, years: median (IQR) & $78(72,84)$ & $73(64,81)$ \\
\hline Male: & $195(45.7)$ & $336(62.2)$ \\
\hline \multicolumn{3}{|l|}{$\begin{array}{l}\text { Initial vitals on index ED } \\
\text { visit, median (IQR) }\end{array}$} \\
\hline Heart rate (beats/min) & $92(81,106)$ & $102(90,115)$ \\
\hline $\begin{array}{l}\text { Systolic blood pressure } \\
(\mathrm{mm} \mathrm{Hg})\end{array}$ & $129(112,144)$ & $134(118,150)$ \\
\hline $\begin{array}{l}\text { Diastolic blood pressure } \\
\qquad(\mathrm{mm} \mathrm{Hg})\end{array}$ & $76(68,89)$ & $80(70,92)$ \\
\hline $\begin{array}{l}\text { Respiratory rate } \\
\text { (breaths/min) }\end{array}$ & $20(18,22)$ & $20(18,20)$ \\
\hline Oxygen saturation (\%) & $96(95,97)$ & $97(96,98)$ \\
\hline Temperature (degrees C) & $36.6(36.4,36.9)$ & $36.7(36.4,36.9)$ \\
\hline \multicolumn{3}{|l|}{ Arrhythmia } \\
\hline Atrial fibrillation & $361(84.7)$ & $450(83.3)$ \\
\hline Atrial flutter & 65 (15.3) & $90(16.7)$ \\
\hline \multicolumn{3}{|l|}{ Duration of symptoms, } \\
\hline Time of onset $<48 \mathrm{~h}$ & $69(16.2)$ & $189(35.0)$ \\
\hline Time of onset $>48 \mathrm{~h}$ & $357(83.8)$ & $351(65.0)$ \\
\hline \multicolumn{3}{|l|}{ Chief complaint, } \\
\hline Palpitations & $57(13.4)$ & $144(26.7)$ \\
\hline Chest pain & $38(8.9)$ & $85(15.7)$ \\
\hline Dyspnea & $120(28.2)$ & 172 (31.9) \\
\hline Weakness & $188(44.1)$ & $121(22.4)$ \\
\hline $\begin{array}{l}\text { Acute focal neurologic } \\
\text { symptom }\end{array}$ & $11(2.6)$ & $8(1.5)$ \\
\hline Other & $12(2.8)$ & $10(1.8)$ \\
\hline \multicolumn{3}{|l|}{ Comorbidities } \\
\hline Prior atrial fibrillation/flutter & 295 (69.3) & $335(62.0)$ \\
\hline Hypertension & $339(79.6)$ & $328(60.8)$ \\
\hline Acute coronary syndrome & $92(21.6)$ & $95(17.6)$ \\
\hline Valvular disease & $76(17.8)$ & $61(11.3)$ \\
\hline Diabetes & $86(20.2)$ & $62(11.5)$ \\
\hline Heart failure & $114(26.8)$ & 102 (18.9) \\
\hline Prior stroke or TIA & $76(17.8)$ & $61(11.3)$ \\
\hline \multicolumn{3}{|l|}{ CHADS 2 score } \\
\hline 0 & $25(5.9)$ & $162(30.0)$ \\
\hline 1 & 72 (16.9) & $131(24.3)$ \\
\hline 2 & $110(25.8)$ & $137(25.4)$ \\
\hline$\geq 2$ & $219(53.2)$ & $107(15.3)$ \\
\hline \multicolumn{3}{|l|}{ Medications } \\
\hline ASA & $142(33.3)$ & $164(30.4)$ \\
\hline Clopidogrel & $15(3.5)$ & $19(3.5)$ \\
\hline Warfarin & 139 (32.6) & 145 (26.9) \\
\hline Beta blocker & $149(35.0)$ & $\begin{array}{l}176 \text { (32.6) } \\
\quad(\text { Continued })\end{array}$ \\
\hline
\end{tabular}

\begin{tabular}{|c|c|c|}
\hline $\begin{array}{l}\text { Characteristic, } n(\%) \\
\text { unless specified }\end{array}$ & $\begin{array}{l}\text { eGFR less } \\
\text { than } 60\end{array}$ & $\begin{array}{l}\text { eGFR } 60 \text { or } \\
\text { greater }\end{array}$ \\
\hline Calcium channel blocker & $68(16.0)$ & $54(10.0)$ \\
\hline Digoxin & $50(11.7)$ & 57 (10.6) \\
\hline Antiarrhythmics & $24(5.8)$ & $45(6.4)$ \\
\hline \multicolumn{3}{|c|}{$\begin{array}{l}\text { Antiarrhythmics }=\text { propafenone, amiodarone, sotalol, flecanide, dronedarone; } A S A= \\
\text { acetylsalicylic acid; } C \text { HADS2 }=\text { heart failure, hypertension, age }>75 \text {, diabetes, stroke } / \mathrm{II} \text {; } \\
\text { EMS = emergency medical services; } \mathrm{TIA}=\text { transient ischemic attack. }\end{array}$} \\
\hline
\end{tabular}

Table 2. Emergency department adverse events (unadjusted) stratified according to estimated glomerular filtration rate, $n=1,112$

\begin{tabular}{|c|c|c|c|}
\hline & $\begin{array}{l}\text { eGFR less } \\
\text { than } 60 \\
(n=412)\end{array}$ & $\begin{array}{l}\text { eGFR } 60 \text { or } \\
\text { greater } \\
(n=700)\end{array}$ & Difference $(95 \% \mathrm{Cl})$ \\
\hline $\begin{array}{l}\text { Total patients } \\
\text { with at } \\
\text { least } 1 \mathrm{AE}\end{array}$ & $39 / 412(9.5)$ & $34 / 700(4.9)$ & 4.6 (1.4 to 8.3 ) \\
\hline $\begin{array}{l}\text { Patients with } \\
\text { no rate or } \\
\text { rhythm } \\
\text { control }\end{array}$ & $13 / 309(4.2)$ & $7 / 462(1.5)$ & $2.7(0.1$ to 5.9$)$ \\
\hline $\begin{array}{l}\text { Patients with } \\
\text { rate or } \\
\text { rhythm } \\
\text { control }\end{array}$ & $26 / 103(25.2)$ & $27 / 238$ (11.3) & 13.9 (4.7 to 24.2 ) \\
\hline \multicolumn{4}{|l|}{ Rate control } \\
\hline Metoprolol & 10/41 (24.4) & $12 / 99(12.1)$ & $12.3(-2.0$ to 29.4$)$ \\
\hline Atenolol & $0 / 2(0.0)$ & $0 / 9(0.0)$ & $0.0(-80.2$ to 37.1$)$ \\
\hline Diltiazem & $4 / 19(21.1)$ & $5 / 42(11.9)$ & $9.2(-11.1$ to 35.3$)$ \\
\hline Verapamil & $1 / 11(9.1)$ & $3 / 21(14.3)$ & $-5.2(-29.8$ to 30.2$)$ \\
\hline Digoxin & $0 / 2(0.0)$ & $0 / 8(0.0)$ & $0.0(-40.3$ to 80.2$)$ \\
\hline $\begin{array}{r}\text { Total rate } \\
\text { control }\end{array}$ & $15 / 75(20.0)$ & 20/179 (11.7) & $8.8(-1.1$ to 20.7$)$ \\
\hline \multicolumn{4}{|l|}{$\begin{array}{l}\text { Rhythm } \\
\text { control }\end{array}$} \\
\hline Electrical & & & countershock \\
\hline 7/16 (43.8) & $4 / 38(10.5)$ & $\begin{array}{l}33.2(5.7 \text { to } \\
59.9)\end{array}$ & \\
\hline Chemical & & & cardioversion \\
\hline 4/12 (33.3) & $3 / 21(14.3)$ & $\begin{array}{l}19.0(-12.9 \text { to } \\
52.0)\end{array}$ & \\
\hline $\begin{array}{l}\text { Total rhythm } \\
\text { control }\end{array}$ & $11 / 28(39.3)$ & $7 / 59$ (11.9) & 27.4 (6.7 to 48.5$)$ \\
\hline $\begin{array}{l}\text { Difference is expre } \\
\text { normal function. }(C \\
A E=\text { adverse event } \\
R R C=\text { rate or rhyth }\end{array}$ & $\begin{array}{l}\text { ed as patients wi } \\
\text { tinuity correction } \\
\text { GFR is the estim } \\
\text { control. }\end{array}$ & $\begin{array}{l}\text { impaired renal functic } \\
\text { ssed.) } \\
\text { ted glomerular filtratio }\end{array}$ & $\begin{array}{l}\text { tion minus patients with } \\
\text { on rate in } \mathrm{mL} / \mathrm{min} / 1.73 \mathrm{~m}^{2} \text {; }\end{array}$ \\
\hline
\end{tabular}




\begin{tabular}{|c|c|c|c|}
\hline & $\begin{array}{l}\text { eGFR less } \\
\text { than } 60 \\
(n=103)\end{array}$ & $\begin{array}{l}\text { eGFR } 60 \\
\text { or greater } \\
(n=238)\end{array}$ & $\begin{array}{l}\text { Difference } \\
(95 \% \mathrm{Cl})\end{array}$ \\
\hline $\begin{array}{l}\text { Total patients } \\
\text { with } \\
\text { treatment } \\
\text { failure, n } \\
(\%)\end{array}$ & $61 / 103(59.2)$ & 78/238 (32.8) & 26.5 (14.5 to 37.6$)$ \\
\hline \multicolumn{4}{|l|}{ Rate control } \\
\hline Metoprolol & 27/41 (65.9) & 37/99 (37.3) & 28.5 (9.0 to 45.0$)$ \\
\hline Atenolol & $1 / 2(50.0)$ & 3/9 (33.3) & $16.7(-42.7$ to 69.9$)$ \\
\hline Diltiazem & 11/19 (57.9) & $12 / 42(28.6)$ & 29.3 (0.04 to 53.6) \\
\hline Verapamil & $5 / 11(45.5)$ & 7/21 (33.3) & $12.2(-24.0$ to 47.0$)$ \\
\hline Digoxin & $1 / 2(50.0)$ & $5 / 8(62.5)-$ & $-12.5(-67.1$ to 47.3$)$ \\
\hline $\begin{array}{l}\text { Total rate } \\
\text { control }\end{array}$ & 45/75 (60.0) & $64 / 179$ (35.8) & 24.3 (10.1 to 37.2$)$ \\
\hline \multicolumn{4}{|l|}{$\begin{array}{l}\text { Rhythm } \\
\text { control }\end{array}$} \\
\hline Electrical & & & countershock \\
\hline 9/16 (56.3) & 3/38 (7.9) & $\begin{array}{l}67.1 \text { (31.8 to } \\
86.3)\end{array}$ & \\
\hline Chemical & & & cardioversion \\
\hline $7 / 12$ (58.3) & 11/21 (51.5) & $\begin{array}{l}18.5(-21.4 \text { to } \\
47.5)\end{array}$ & \\
\hline $\begin{array}{l}\text { Total rhythm } \\
\text { control }\end{array}$ & 16/28 (57.1) & 14/59 (23.7) & 33.4 (9.7 to 53.7) \\
\hline $\begin{array}{l}\text { Difference is expr } \\
\text { normal function. ( } \\
\text { eGFR is the estim }\end{array}$ & $\begin{array}{l}\text { dis patients w } \\
\text { tinuity correction } \\
\text { glomerular filtra }\end{array}$ & $\begin{array}{l}\text { nimpaired renal functic } \\
\text { used.) } \\
\text { on rate in } \mathrm{mL} / \mathrm{min} / 1.73\end{array}$ & $\begin{array}{l}\text { tion minus patients with } \\
73 \mathrm{~m}^{2}\end{array}$ \\
\hline
\end{tabular}

received $\mathrm{RRC}$ is $11.8 \%$ (95\% CI 0.7 to $23.9 \%$ ), the excess population attributable risk for RRC was $9.0 \%$ (95\% CI 1.0 to $18.8 \%$ ), and the excess exposure effect of RRC was $13.7 \%$ (95\% CI 1.7 to $25.1 \%$ ). When comparing patients with low versus normal eGFR, the adjusted odds ratio for RRC treatment failure was 3.11. (95\% CI 1.79 to 5.57) (Table 4; stepwise calculations in Appendix 3.)

The secondary analysis of 581 patients (18 [3.1\%] excluded due to missing covariates) had similar results for both excess AE risk and treatment failure. The sensitivity analysis of 885 patients also had similar results for both outcomes (see Table 4 and Appendix 3).

\section{DISCUSSION}

In this cohort of 1,112 consecutive ED patients with AFF, over one-third had low eGFR and such patients were older with more cardiovascular comorbidities. The crude AE rate for AFF patients with low eGFR undergoing $\mathrm{RRC}$ is approximately $25 \%$ - rising to $50 \%$ at the lowest eGFR - a far higher rate than seen in other AFF groups. ${ }^{17,18}$ The crude RRC treatment failure for patients with low eGFR was nearly $60 \%$.

We measured the influence of low eGFR upon RRC administration in AFF patients in three analyses, and, after controlling for baseline imbalances, $\mathrm{AE}$ rates were higher than had RRC not been administered. ${ }^{1}$ The excess RRC risk was $12 \%$, indicating that, had RRC theoretically been administered to every patient, there would have been $12 \%$ more $\mathrm{AE}$ in the low-eGFR group than the normal-eGFR group, than if RRC had not been administered to anyone. This implies that $\mathrm{RRC}$ has a greater $\mathrm{AE}$ effect upon patients with low eGFR. ${ }^{2}$ Because not all patients had RRC, the population attributable risk difference implies that the actual excess RRC risk for our study patients was $9 \% .^{3}$ The exposure effect estimates that there is a nearly $14 \%$ excess risk when RRC is used in patients with low versus normal eGFR. Combined, these results, all statistically significant with the same clinical trend, indicate

Table 4. Adjusted outcomes with $95 \%$ confidence intervals in main and secondary analyses, $n=1,112$ overall

\begin{tabular}{|c|c|c|c|}
\hline & $\begin{array}{l}\text { Main analysis } \\
(n=1,031)\end{array}$ & $\begin{array}{l}\text { Initial } h r>100 \text { or } \\
\operatorname{RRC}(n=563)\end{array}$ & $\begin{array}{l}\text { Complete data } \\
(\mathrm{n}=885)\end{array}$ \\
\hline \multicolumn{4}{|l|}{ Excess AE risk in low versus normal eGFR (\%) } \\
\hline Causal risk difference & $11.8(0.7$ to 23.9$)$ & 15.4 (18 to 27.3 ) & $11.5(-0.4$ to 23.7$)$ \\
\hline Population attributable risk & 9.0 (1.0 to 18.8$)$ & $7.9(1.2$ to 14.2$)$ & 8.9 (0.1 to 18.5$)$ \\
\hline Exposure risk in patients with $\mathrm{RRC}$ & $13.7(1.7$ to 25.1$)$ & 14.6 (1.8 to 25.9$)$ & 13.5 (1.1 to 24.8$)$ \\
\hline Odds ratio of treatment failure for low versus normal eGFR & 3.11 (1.79 to 5.57$)$ & $3.07(1.71$ to 5.52$)$ & $3.08(1.72$ to 5.53$)$ \\
\hline
\end{tabular}


that administration of RRC in AFF patients with low eGFR is associated with a $9 \%-14 \%$ increase in $\mathrm{AE}$ rates when compared with RRC administration in patients with low eGFR. Furthermore, there is a threefold adjusted odds ratio of RRC treatment failure in loweGFR patients. Our secondary analysis of patients with initial tachycardia or receiving rhythm or rate control had similar results, and our sensitivity analysis also supports these conclusions. These results should encourage clinicians to be very cautious in administering RRC treatments in AFF patients with low eGFR.

It is important to note that these data reflect a population, and that select low eGFR-patients may in fact be at lower risk than normal eGFR-patients. To illustrate, it may be safer to administer rate control in a 55 -year-old male with eGFR 59 than a hypotensive, hypoxic 90-year-old male with eGFR 60. Thus, although low eGFR is generally associated with worse outcomes, physicians must still regard this variable in the overall clinical context; other characteristics such as age and comorbidities also remain important. ${ }^{4}$

We purposely combined patients with primary AFF presentations and with AFF precipitated by or concomitant with another acute condition. The latter group is likely sicker, and ED physicians should strive to identify underlying acute illnesses prior to initiation of AFFspecific treatment. ${ }^{10}$ There is likely overlap between patients with low eGFR and those with an underlying illness. However, distinguishing patients with AFF only (whether with low or normal eGFR), those with AFF and an underlying illness and acute low eGFR, ${ }^{25}$ and those with $\mathrm{AFF}$ and an underlying illness worsening chronic low eGFR can be very challenging in practice. Clinical histories, including prior eGFR, may not be available, ominous conditions such as sepsis may not declare themselves for many hours, ${ }^{27}$ and often important ED AFF management decisions such as RRC are made very early during the ED encounter. ${ }^{10}$ Thus, the eGFR, a test that typically returns quickly, can be an important early clue that the patient is sicker (or healthier) than an initial physician assessment might indicate.

Previous data have shown that an ED serum creatinine $>200 \mathrm{umol} / \mathrm{L}$ increases 90-day mortality risk for ED AFF patients. ${ }^{16}$ However, there is no prior data demonstrating an association between low eGFR and higher ED-based AE rates and treatment failures, which emergency physicians may have some control over. While recent ED guidelines identify a vulnerable group of ED AFF patients (with acute underlying medical conditions), using characteristics such as age and cardiovascular comorbidities, ${ }^{4}$ there is no mention of low eGFR. Our study extends these findings by demonstrating that across a population of AFF patients with low eGFR, RRC is more likely to be associated with increased $\mathrm{AE}$ and treatment failure.

\section{Limitations}

The findings in this review of two urban Canadian EDs may be challenging to extrapolate. In particular, the proportion of patients with low eGFR may be higher than in other hospitals. We assumed patients without a recorded eGFR had normal renal function because only a small number had an $\mathrm{AE}$ and none were admitted, and our sensitivity analysis supports this. The MDRD equation was derived and validated in stable patients with chronic kidney disease, ${ }^{19}$ and its applicability in ED patients is unknown. Our definition of low eGFR $(<60 \mathrm{ml} / \mathrm{min} /$ $1.73 \mathrm{~m}^{2}$ ) reflects a stage of illness progression in outpatients with chronic kidney disease, and thus may misclassify some ED patients as high- or low-risk. We combined all patients with low eGFR, rather than distinguishing between acute and chronic renal insufficiency, to examine the risks associated with any renal insufficiency. This approach has been adopted in other ED cardiovascular cohort studies. ${ }^{26}$ Owing to small sample size but similar to a prior analysis, ${ }^{10}$ we combined rate control, chemical conversion, and electrical conversion. It is possible that unmeasured confounders, for example, physician ${ }^{10}$ or patient preference for RRC, or timing of RRC, ${ }^{10}$ influenced results, but our secondary analysis focusing on patients with higher heart rates and those who underwent RRC, should help ameliorate this concern.

\section{CONCLUSION}

In this cohort of ED AFF patients administered RRC, those with low eGFR had significantly increased adjusted excess risk of AE when compared with patients with normal renal function. Odds of treatment failure were also significantly increased.

\section{SUPPLEMENTARY MATERIAL}

The supplementary material for this article can be found at https://doi.org/10.1017/cem.2018.475. 


\section{Competing interests: None declared.}

Acknowledgements: FS conceived the idea, designed the study, and composed the first draft. EG provided source data. HW and MW performed statistical analysis, while TB, JC, BG, and especially GI provided critical editorial input.

The authors gratefully acknowledge the contributions of Reza Pourvali, MD; Clare Heslop, MD, PhD; Jan McPhee, MD, MSc; Brett Heilbron, MD; and John Ward, MD.

\section{REFERENCES}

1. McDonald AJ, Pelletier AJ, Ellinor PT, et al. Increasing US emergency department visit rates and subsequent hospital admissions for atrial fibrillation from 1993 to 2004. Ann Emerg Med 2008;51:58-65.

2. Connolly S, Gillis A. 2004 CCS Consensus Conference on Atrial Fibrillation. Therapies for the prevention of stroke and other vascular events in atrial fibrillation and flutter. Can 7 Cardiol 2005;21(Suppl B):71B-3B.

3. Heilbron B, Klein GJ, Talajic M, et al. 2004 CCS Consensus Conference on Atrial Fibrillation. Management of atrial fibrillation in the emergency department and following acute myocardial infarction. Can 7 Cardiol 2005;(21 Suppl B)71B-3B.

4. Stiell IG, Scheuermeyer FX, Vadeboncouer A, et al. CAEP acute atrial fibrillation/flutter best practices checklist. CFEM 2018;20(3):334-342.

5. Cairns JA, Connolly SJ, McMurtry S, et al. Canadian Cardiovascular Society atrial fibrillation guidelines 2010: prevention of stroke and systemic thromboembolism in atrial fibrillation and flutter. Can 7 Cardiol 2011;27:74-90.

6. Fuster V, Ryden LE, Cannom DS, et al. ACC/AHA/ESC 2006 guidelines for the management of patients with atrial fibrillation. Circulation 2006;114:700-52.

7. Wann LS, Curtis AB, January CT. 2011 ACCF/AHA/HRS focused update on the management of patients with atrial fibrillation (updating the 2006 guideline). $7 \mathrm{Am}$ Coll Cardiol 2011;57:223-42.

8. Skanes AC, Healy JS, Cairns JA, et al. Focused 2012 update of the Canadian Cardiovascular Society Atrial Fibrillation Guidelines: recommendations for stroke prevention and rate/rhythm control. Can 7 Cardiol 2012;28:125-36.

9. Atzema CL, Lam K, Young C, et al. Patients with atrial fibrillation and an alternative primary diagnosis in the emergency department: a description of their characteristics and outcomes. Acad Emerg Med 2013;20:193-200.

10. Scheuermeyer FX, Pourvali R, Rowe BH, et al. Emergency department patients with atrial fibrillation or flutter and an acute underlying medical illness may not benefit from attempts to control rate or rhythm. Ann Emerg Med 2015;65:511-22.e2.

11. Nakagawa K, Hirai T, Takashima S, et al. Chronic kidney disease and CHADS 2 score independently predict cardiovascular events and mortality in patients with nonvalvular atrial fibrillation. Am 7 Cardiol 2011;107:912-6.

12. Piccini JP, Stevens SR, Chang Y, et al. Renal dysfunction as a predictor of stroke and systemic embolism in patients with nonvalvular atrial fibrillation: validation of the R2CHADS2 index in the ROCKET-AF and ATRIA study cohorts. Circulation 2013;127:224-32.

13. Andersson T, Magnuson A, Bryngelsson IL, et al. All-cause mortality in 272186 patients hospitalized with incident atrial fibrillation 1995-2008: a Swedish nationwide long-term casecontrol study. Eur Heart 7 2013;34(14):1061-7.

14. Fox KA, Piccini JP, Wojdyla D, et al. Prevention of stroke and systemic embolism with rivaroxaban compared with warfarin in patients with non-valvular atrial fibrillation and moderate renal impairment. Eur Heart 7 2011;32:2387-94.

15. Oleson JB, Kip GY, Kamper AL, et al. Stroke and bleeding in atrial fibrillation with chronic kidney disease. NEFM 2012;367:625-35.

16. Atzema CL, Lam K, Young C, Kester-Greene N. Patients with atrial fibrillation and an alternative primary diagnosis in the emergency department. A description of their characteristics and outcomes. Acad Emerg Med 2013;20:193-9.

17. Scheuermeyer FX, Grafstein E, Stenstrom R, et al. Thirty day and one-year outcomes of emergency department patients with atrial fibrillation and no acute underlying medical cause. Ann Emerg Med 2012;60:755-62.e2.

18. Scheuermeyer FX, Grafstein E, Stenstrom R, et al. Safety and efficiency of calcium channel blockers versus beta-blockers for rate control in patients with atrial fibrillation and no acute underlying medical illness. Acad Emerg Med 2013;20:222-30.

19. Levey AS, Bosch JP, Lewis JB, et al. A more accurate method to estimate glomerular filtration rate from serum creatinine: a new prediction equation. Modification of Diet in Renal Disease Study Group. Ann Intern Med 1999;130:461-70.

20. Gilbert EH, Lowenstein SR, Koziol-McLain J, et al. Chart reviews in emergency medicine research: where are the methods? Ann Emerg Med 1996;27:305-8.

21. Worster A, Bledsoe RD, Cleve P, et al. Reassessing the methods of medical record review studies in emergency medicine research. Ann Emerg Med 2005;45:448-51.

22. Gage BF, Waterman AD, Shannon C, et al. Validation of clinical classification schemes for predicting stroke. Results from the National Registry of Atrial Fibrillation. 7AMA 2001;285:2864-70.

23. Levey AS, Becker C, Inker LA. Glomerular filtration rate and albuminuria for detection and staging of acute and chronic kidney disease in adults. $7 A M A$ 2015;313:834-46.

24. Chronic kidney disease: early identification and management of chronic kidney disease in adults in primary and secondary care; 2013. Available at: http://www.kdigo.org/clinical_practice_ guidelines/pdf/CKD/KDIGO_2012_CKD_GL.pdf (accessed May 1, 2018).

25. Lassnigg A, Schmidlin D, Mouhieddine M, et al. Minimal changes of serum creatinine predict prognosis in patients after cardiothoracic surgery: a prospective cohort study. 7 Am Soc Nephrol 2004;15:1597-1605.

26. Greenslade JH, Cullen L, Kalinowski L, et al. Examining renal impairment as a risk factor for acute coronary syndrome. A prospective observational study. Ann Emerg Med 2013;62:38-46.e1.

27. Villar J, Clement JP, Stotts J, et al. Many emergency department patients with severe sepsis and septic shock do not meet diagnostic criteria within three hours of arrival. Ann Emerg Med 2014;64:48-54. 